\title{
(2) canem \\ ○ OPEN ACCESS \\ Unusual presentation of a large GIST in an extraintestinal site: a challenging diagnosis dilemma
}

\author{
Arwa Ahmed Ashoor 다, ${ }^{1}$ Ghaith Barefah²
}

${ }^{1}$ Department of Surgery, King Fahad General Hospital, Jeddah, Saudi Arabia

${ }^{2}$ Department of Radilogy, King Fahad General Hospital, Jeddah, Saudi Arabia

Correspondence to Dr Arwa Ahmed Ashoor: arwa_ashoor@hotmail.com

Accepted 14 January 2020
Check for updates

(c) BMJ Publishing Group Limited 2020. Re-use permitted under CC BY-NC. No commercial re-use. See rights and permissions. Published by BMJ.

To cite: Ashoor AA,

Barefah G. BMJ Case

Rep 2020;13:e229839.

doi:10.1136/bcr-2019

229839

\section{SUMMARY}

Gastrointestinal stromal tumour (GIST) is a recent recognised tumour entity. In the past, those tumours were classified as leiomyomas, leiomyosarcomas and leiomyoblastomas, but it is now evident that GIST is a separate tumour entity and is the most common sarcoma of the gastrointestinal tract especially with advances in immunohistochemical staining techniques and improvements in microscopic structural imaging. We present a case of GIST of unusual location and presentation pattern, with an overview over current GISTs' diagnosis and management strategies. The precise incidence and tumour behaviour of rare extragastrointestinal stromal tumour (EGIST) remain to be clarified. Further research is needed in large series with long duration of follow-up and modified risk stratification assessment tailored for EGISTs.

\section{BACKGROUND}

Gastrointestinal stromal tumour (GIST), a rare recognised entity until 2000, the era that has marked the discovery of an activating mutation of the c-kit tyrosine kinase found in almost all GIST tumours and the ability to target those mutations with the specific tyrosine kinase inhibitor (imatinib mesylate). ${ }^{12}$

GIST tumours now represent approximately about $3 \%-5 \%$ of all soft tissue sarcomas, respectively 3\% of gastrointestinal (GI) tumours. ${ }^{2}$ Most GISTs arise from the stomach (50\%-70\%) and small intestine (20\%-30\%), including the duodenum, jejunum and ileum. Other locations are the large intestine (5\%), and the oesophagus in $2 \%-5 \%$ of cases. ${ }^{2} 3$ Small numbers of extragastrointestinal stromal tumours (EGISTs) have been reported in the literature; most of those were case reports or cohort analysis (Mettinen et al, analysis of 112 cases) where clinicopathologic correlation and long-term follow-up data of such tumours are scant. ${ }^{4}$ Other groups (FanFing and colleagues, analysis of 114 mesenteric GIST) have reported EGISTs in other rare sites such as in mesenteric location. ${ }^{5}$

\section{CASE PRESENTATION}

A 67-year-old male patient referred from urology service where he was following for benign prostatic hyperplasia (BPH), when an incidental finding of a right iliac fossa (RIF) mass was noted on ultrasound (US) study. The patient reported to have a 1-year history of progressive growing of a painless abdominal mass; he denied any abnormal bowel habits or any other symptoms. The patient's relevant history included diabetes mellitus (DM), hypertension (HTN), mild renal impairment. Of notice, he underwent resection of a small bowel tumour 20 years ago in another facility when he presented with upper GI bleeding and shock. At that time, a bleeding jejunal tumour was resected and the final histopathology reported smooth muscle tumour of undetermined malignant potential (SMTUMP). No further treatment was given afterwards and the patient reported living a normal life. On physical examination, a large solid, illdefined non-tender mass was found, measuring around $13 \mathrm{~cm}$ in diameter, occupying the RIF and the lower abdomen. Completed work up resulted in unremarkable colonoscopy and tumour markers (CEA, CA 19.9, AFP).

\section{INVESTIGATIONS}

Requested abdominal US (figure 1), showed a welldefined heterogeneous slightly echogenic solid mass with bull's eye appearance and a central necrotic geographic area likely representing a central ulceration. It showed no significant flow on colour Doppler which is typical for large GISTs. ${ }^{6}$ The mass measured $11.3 \times 12.7 \times 14 \mathrm{~cm}^{3}$. Mural nodules were noticed, likely originating from the mesentery or the retroperitoneum

A non-enhanced CT scan of the abdomen and pelvis with oral contrast (figure 2) revealed a large low attenuated right midline pelviabdominal extraintestinal mass with left dense lobule or mural nodule (arrow). The origin of the mass was likely from the mesentery or the retroperitoneum anterior to the aortic bifurcation. The lesion measured $17.6 \times 17.6 \times 11 \mathrm{~cm}^{3}$. It had no connection to adjacent bowel or organs.

MRI of abdomen and the pelvis (figure 3 ) showed a necrotic mass originating from the mesentery or the retroperitoneum containing internal debris, ulceration and septations.

The solid component in the mass showed hypointense signal in T2 WIs (A-D), which was more prominent on the left side with a nodule likely representing fibrous tissues. It appeared as well hypovascular $(G)$ with progressive enhancement in the delayed sequences $(\mathrm{H})$, and showed small areas of restrictive diffusion in the left mural nodule (E and F, white arrows). The cystic components showed T2 shine through effect. 

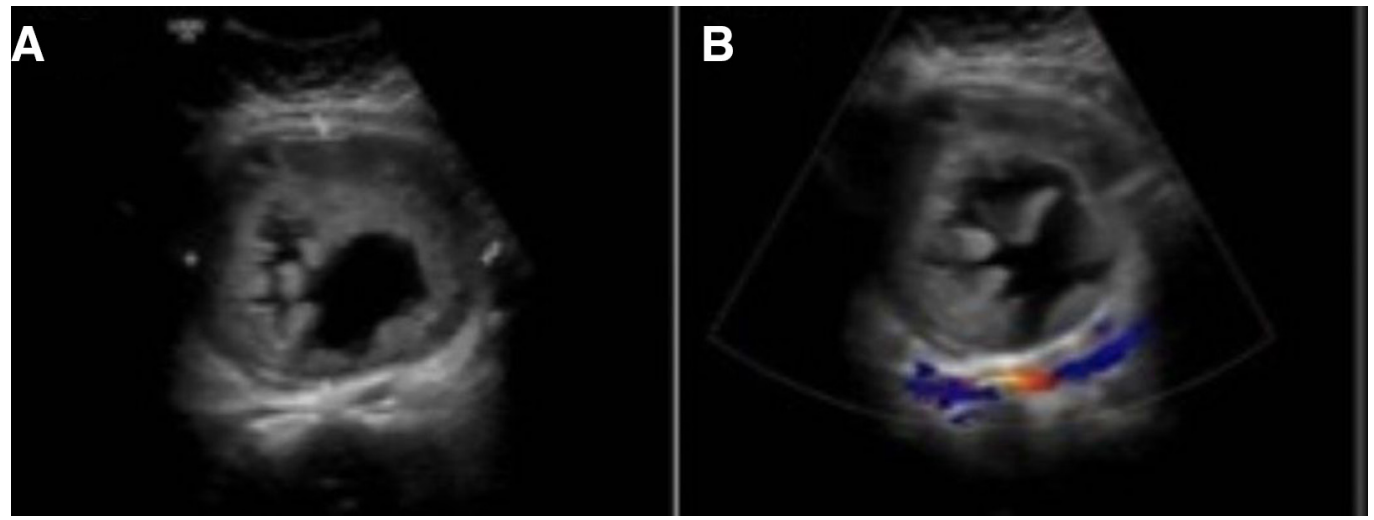

Figure 1 (A) Transverse grey scale ultrasound (US). (B) Colour Doppler US.

\section{TREATMENT}

The patient underwent laparotomy exploration, where a giant whitish well encapsulated solid mass was found as shown in figure 4, measuring around $15 \mathrm{~cm}$ in diameter. The mass was not invading nearby organs or structures. It had a posterior attachment to the pelvic retroperitoneum (figure 5), from which it was separated completely. Completed exploration to the peritoneal cavity showed no other abnormality. The intraoperative picture suggested an extragastrointestinal retroperitoneal tumour.

\section{DIFFERENTIAL DIAGNOSIS}

Pathological examination of the tumour reported a $15 \mathrm{~cm}$, cystic well encapsulated tumour with a thickened wall of $12 \mathrm{~mm}$. On cross section, the tumour had a fleshy granularity with multiple pale areas of necrosis and reddish regions of haemorrhage which was suggestive of GIST. ${ }^{4}$ Microscopic examination showed marked haemorrhagic and cystic degeneration. Spindle cells were having cigar shaped nuclei and pale eosinophilic cytoplasm

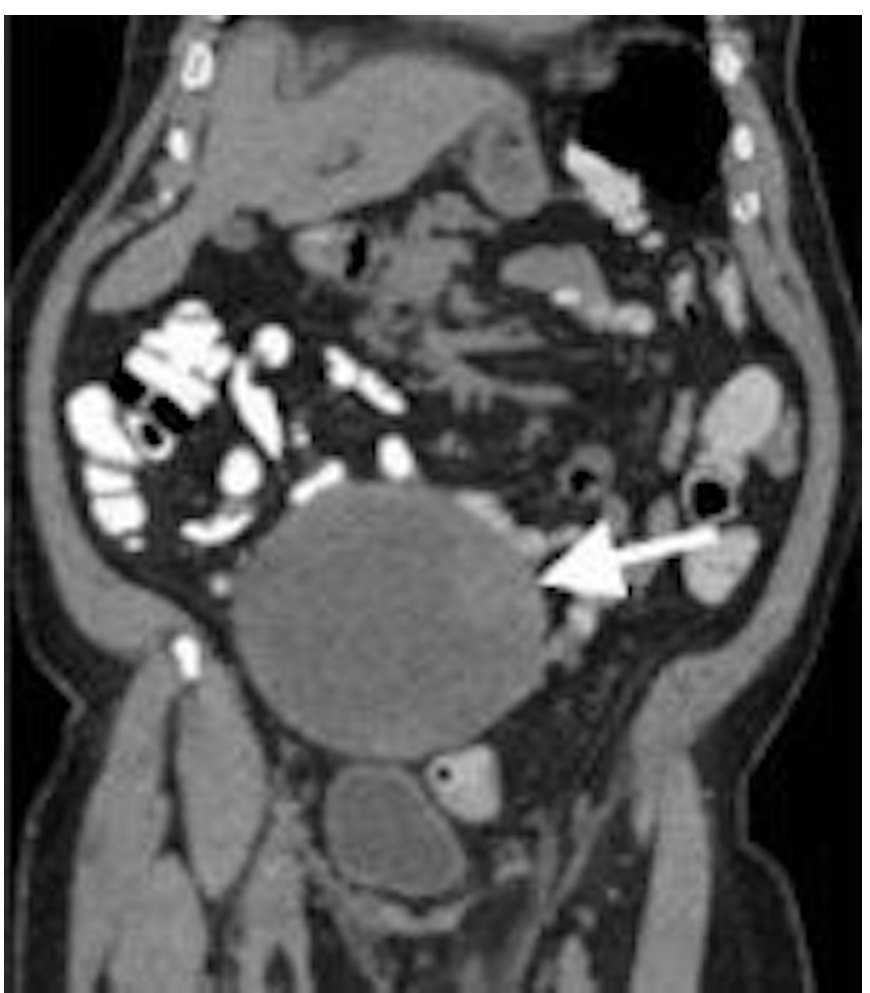

Figure 2 Coronal non-enhanced abdominal CT scan. with indistinct membrane. In between, chronic inflammatory cells composed of lymphocytes were seen. No atypia was present, minimal mitosis 2/50 high power fields (HPFs) was noted and margin was free of tumour cells (figure 6). Immunohistochemistry (IHC) stained negative for actin and $\beta$-catenin in spindle cells and CD117 stained positive (figure 7). Given the above-mentioned characteristic of the tumour, tumour cells and a positive stain of CD117, the overall picture suggested a retroperitoneal EGIST.

\section{OUTCOME AND FOLLOW-UP}

At the time of this report, the patient is 5-month post-operation. He was referred to oncology service for adjuvant treatment, which was considered due to large tumour size and his history favouring a theory of recurrent GIST. A hypothesis was proposed that his resected small bowel tumour 20 years ago which was diagnosed as SMTUMP at that time, when IHC analysis methods were not available and before the evolution of imatinib, was a primary GIST tumour with a slow malignant potential, and that his current presentation of an extraintestinal tumour mass is a latent recurrence rather than a primary EGIST. He is now receiving GLEEVEC (imatinib mesylate) tablets $400 \mathrm{mg}$ per day for an estimated duration of 3 years. His recent CT scan of abdomen, pelvis and chest during follow-up showed no evidence of tumour recurrence (figure 8).

\section{DISCUSSION}

GIST's particular clinical features, histological and uncommon molecular characteristics, have led many to consider separating it from the usual smooth muscle tumours into a specific entity. ${ }^{12}$ A striking, uniform immunoreactivity for kit receptor (CD 117) marked such stromal tumour, which was abscent in other types smooth muscle, Schwannian tumours of the GI tract and other sarcomas of the GI tract. ${ }^{7}$ GISTs show morphological and immunophenotypic similarities with intestinal cell of cajal, a pacemaker system in the GI tracts. ${ }^{24}$

Differential diagnosis of GISTs has been very much facilitated by IHC test, using a complete and specific panel of antibodies for mesenchymal tumours. Most GISTs (>90\%) show overexpression of the receptor tyrosine kinase KIT (CD117) by IHC, a proportion of GISTs (5\%) which are CD117-negative exists. ${ }^{23}$

Approximately $70 \%$ of GISTs express CD34 and may express smooth muscle actin on IHC. ${ }^{17}$ Other commonly used markers include caldesmon, S-100 (a neural cell marker) protein and keratin, which can be variably immunoreactive in GISTs. ${ }^{8}$ Differential diagnosis includes tumours with nervous differentiation: 

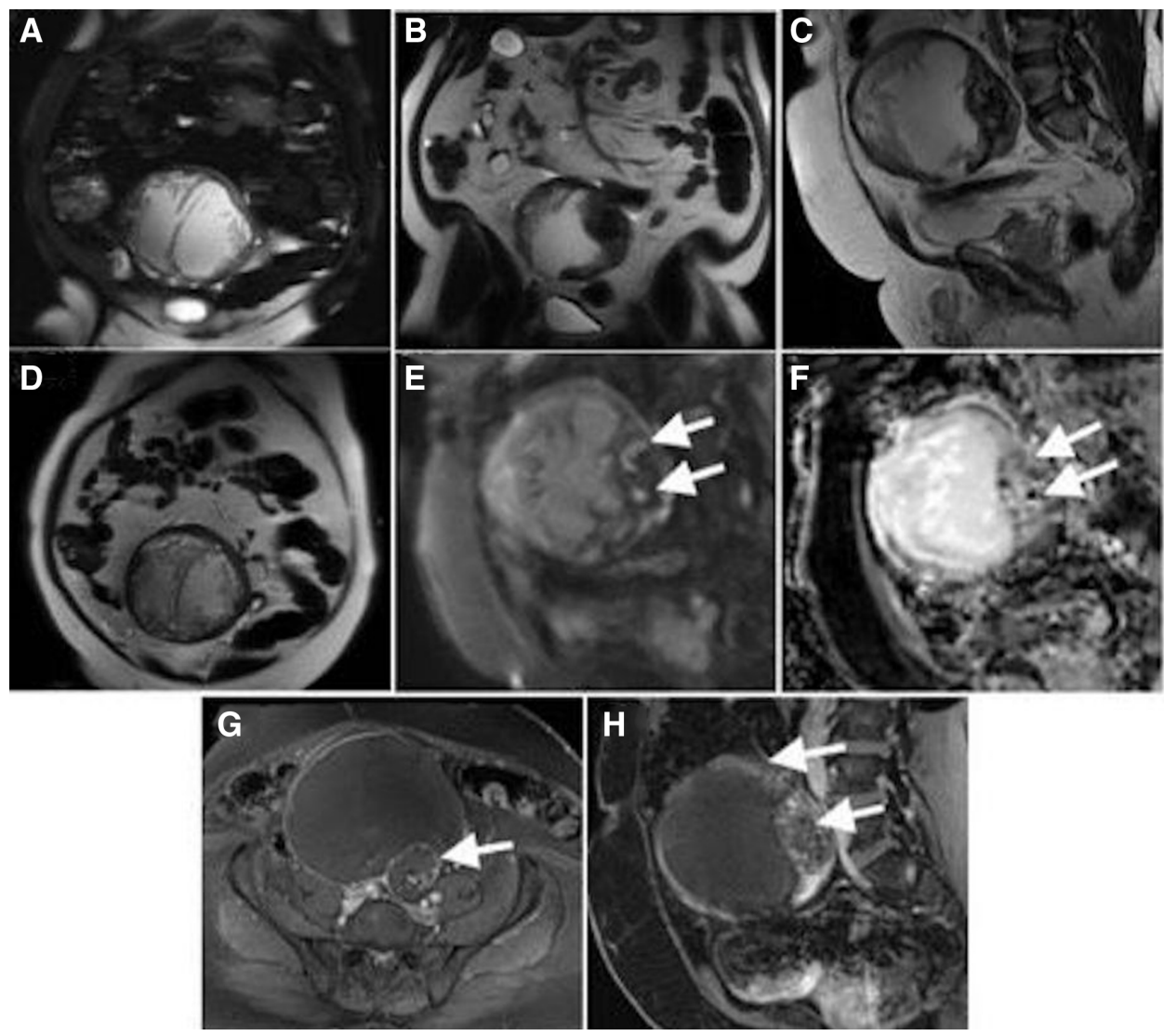

Figure 3 (A) MRI abdomen coronal T2 fat saturation. (B-D) Coronal and sagittal T2 MRI. (E, F) Sagittal diffusion and ADC map MRI sequences. (G, $\mathrm{H}$ ) Axial and sagittal T1 fat saturation post gadolinium contrast administration MRI shows the progressive enhancement of the wall and mural nodule (arrows).

gastric schwannomas (intensely positive for S100-protein, but negative for CD117), tumours with fibrous differentiation such as intra-abdominal fibromatosis, which affects the stomach (CD117-negative), inflammatory gastric polyp and inflammatory myofibroblastic pseudo-tumour (both negative for CD117 and CD34). IHC can also exclude the retroperitoneal undifferentiated liposarcoma, and the other two mesenchymal tumours positive for c-kit: metastases of malignant melanoma (HMB45 and Melan A-positive) and angiosarcoma (CD31-positive). ${ }^{9}$

GIST tumours are well defined, not encapsulated, firm in consistency and whitish in colour. Small lesions have a homogeneous aspect on overall section surface, while large lesions may present with zones of necrosis, haemorrhage and cystic degeneration. Grossly, they appear fleshy pink or tan-white cut surface with haemorrhagic foci. Microscopically, they can have a moderate or high cellularity, and can be divided into spindle cell, epithelioid, signet ring cell, pleomorphic, oncocytic variants or those with myxoid stroma variant. ${ }^{289}$

Small size GISTs can be discovered incidentally during imaging or endoscopy. Symptoms vary depending on the location and size of the tumour, those related to the tumour mass effect (abdominal pain, discomfort, distension and a palpable mass), or others presenting with anaemia and GI haemorrhage. ${ }^{1011}$

Contrast-enhanced abdominal and pelvic CT scan is the investigation of choice for staging and follow-up. MRI may be an alternative such as for rectal GISTs. Chest CT scan and routine laboratory testing complement the staging work up. Evaluation of fluorodeoxyglucose (FDG) uptake using an FDG-positron emission tomography (PET) scan, or FDG-PET-CT/MRI, is useful for early detection of tumour response to moleculartargeted therapy or neoadjuvant therapy. ${ }^{11} 12$

On imaging, the 'Embedded organ' sign is a useful and valid tool for identifying the organ of origin. ${ }^{13}$ GIST usually shows intense homogeneous enhancement; however larger lesions show necrosis and appear heterogeneous and hypovascular. ${ }^{14-16}$ The EGISTs still have no typical radiological features and they have a non-specific appearance with wide deferential diagnosis including leiomyosarcoma, fibrosarcoma, liposarcoma, solitary fibrous tumour, paragnglioma, schwannoma and lymphoma. EGIST presenting as a mass in the omentum, peritoneum or retroperitoneum could be a primary GIST or a metastatic one. ${ }^{17}$

Metastases in GISTs have been reported in 50\% of the patients. The liver is the organ with the most frequent metastases $(65 \%)$, followed by the peritoneum (21\%). Metastases to lymph nodes, lungs and bones are considered rare sites. ${ }^{211}$ The question in our case is whether it is a primary EGIST or a latent recurrence from a previous small intestinal GIST diagnosed in the past as SMTUMP.

Noted that small $(<1 \mathrm{~cm})$ incidentally found GISTs behave almost invariably in a benign fashion, while tumours arising from the small bowel, colon, rectum or mesentery are generally associated with less favourable outcome than those arising from the stomach. ${ }^{11}$ Rare GISTs, referred as EGISTs, that arise in the abdominal cavity outside of the GI tract were associated with the most unfavourable outcome, while some EGISTs might have been metastasised from an undetected primary tumours. ${ }^{18}$

Estimating the risk of recurrence is an important factor as many GISTs have an uncertain malignant potential. Adjuvant 


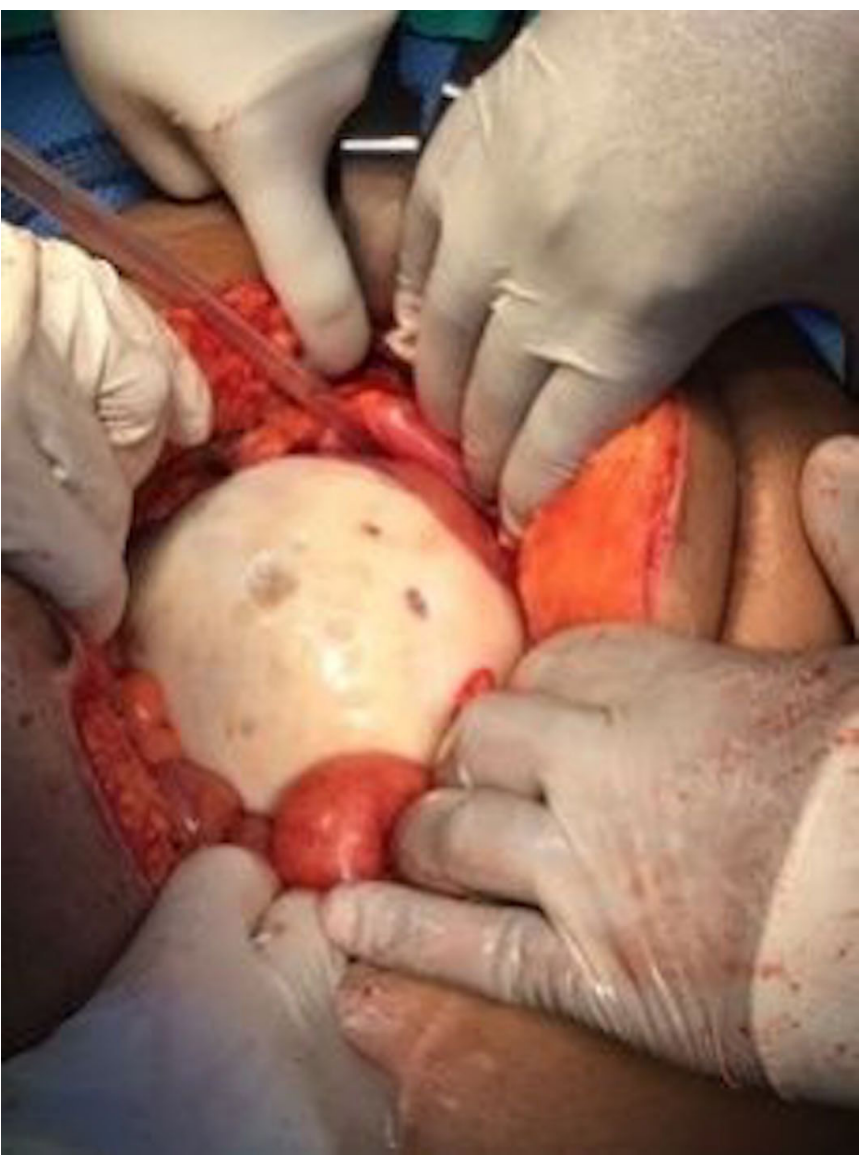

Figure 4 Whitish well encapsulated tumour.

therapy has become a standard praxis in the management of such tumours, and it can be used as a guide for risk of recurrence. ${ }^{2} 10$ Several risk stratification factors have been proposed (table 1): the National Institute of Health (NIH) consensus criteria, the modified NIH consensus criteria and the Armed Forces Institute of Pathology criteria. Risk factors incorporated included; tumour size and site, mitotic count per HPFs and tumour

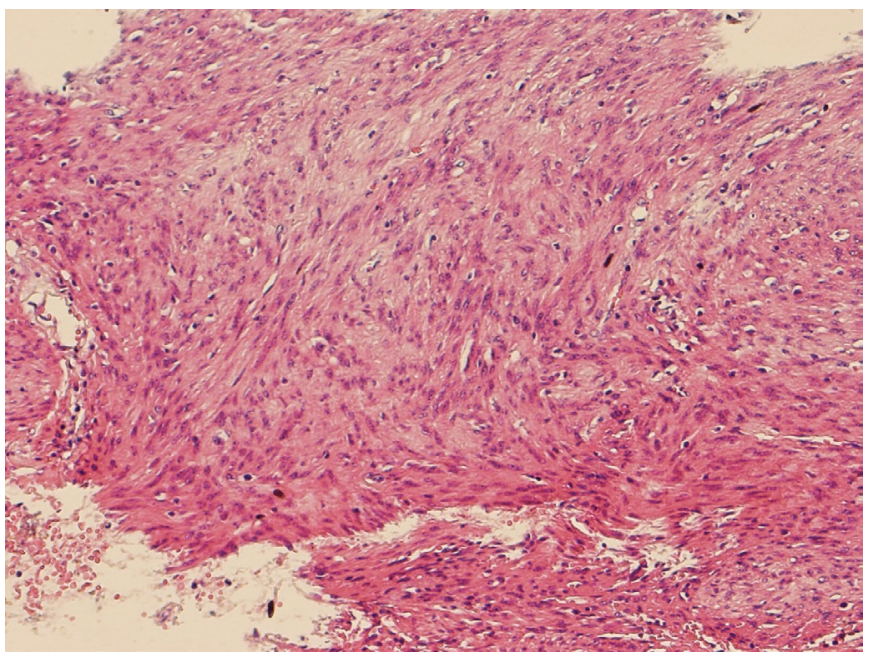

Figure 6 Microscopic histopathology showing streaming bundles of bland looking delicate spindle cells with faint eosinophilic cytoplasm and inconspicuous nucleoli, overt perinuclear clearing (halos) and no brisk mitotic activity.

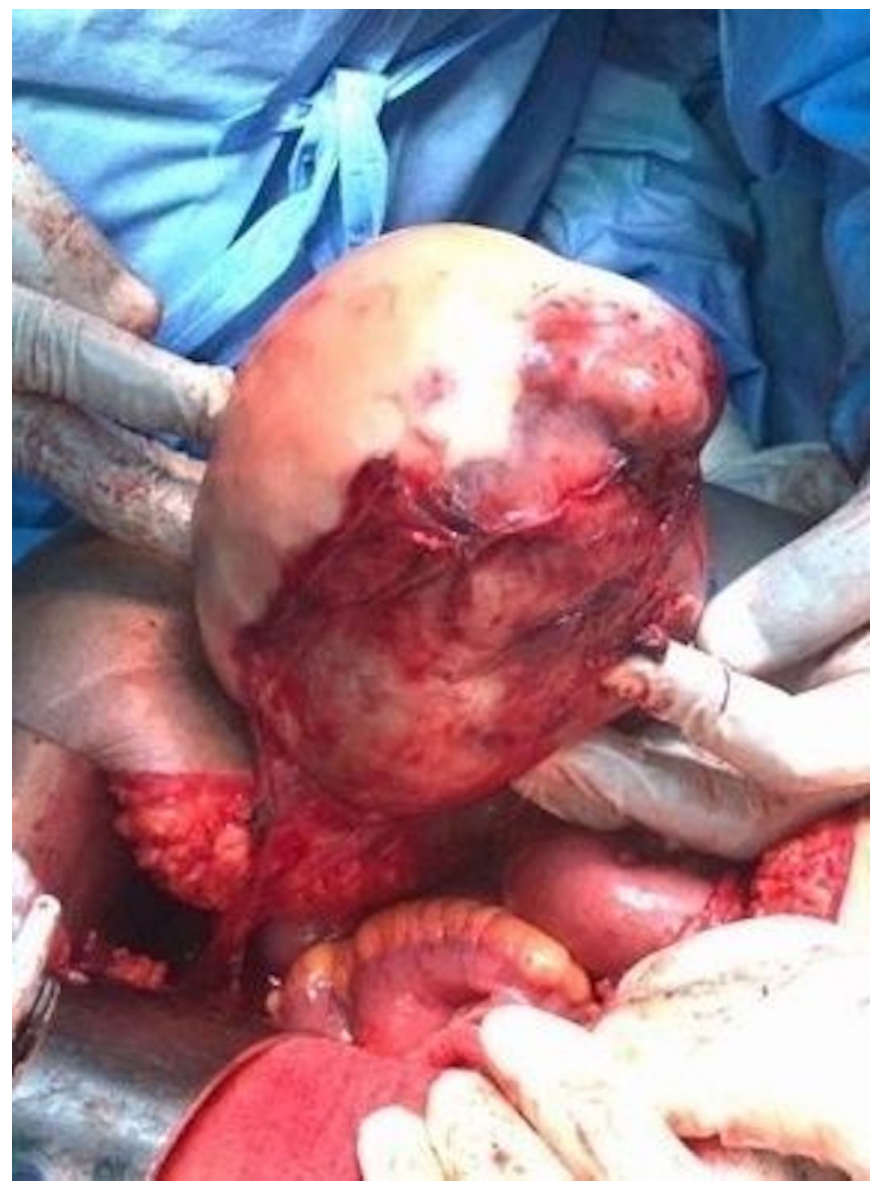

Figure 5 The mass had no attachment to nearby structures; it had only a posterior attachment to the retroperitoneum shown in the picture.

rupture. $^{212}$ 18-20 The TNM classification for staging has several limitations and its use is not recommended in this disease. ${ }^{10}$

Mutational analysis can play a rule in GIST, as mutations involving KIT and PDGFRA can confirm the diagnosis of GIST if doubtful and in rare cases of CD117/DOG1-negative suspected GIST, which are of 5\% incidence. It has as well a predictive value for the sensitivity to molecular-targeted therapy and a prognostic

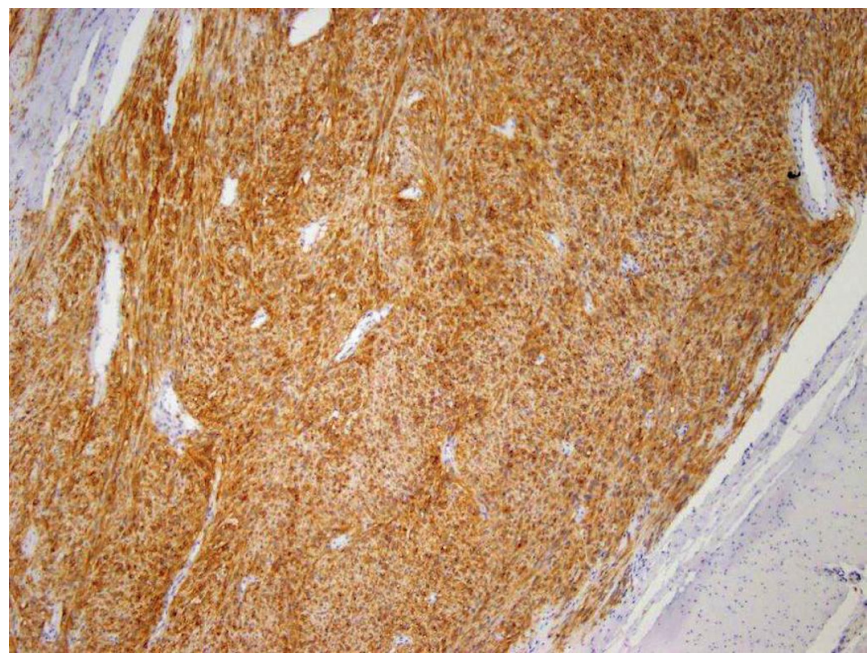

Figure 7 Immunohistochemistry showing expression of CD117 marker in tumour cells. 


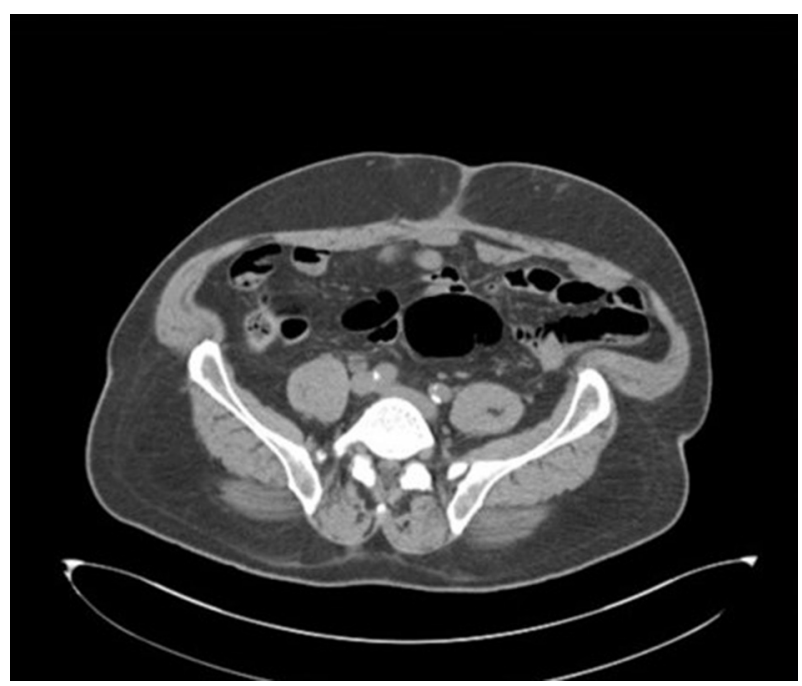

Figure 8 Non-enhanced 6-month follow-up CT scan shows no local recurrence.

Table 1 Stratification schemes for GIST recurrence used in some studies. (Adopted from Joensuu, Heikki, et al. 'risk of recurrence of gastrointestinal stromal tumour after surgery: an analysis of pooled population-based cohorts.' The Lancet Oncology, vol. 13, no. 3, 2012, PP. 265-274, doi:10.1016/s1470-2045(11)70299-6.)

\begin{tabular}{|c|c|c|c|}
\hline & \multicolumn{3}{|c|}{$\begin{array}{l}\text { Tumour characteristic } \\
\text { Size }(\mathrm{cm}) \text { mitosis count/site } \\
50 \text { high power fields }\end{array}$} \\
\hline \multicolumn{4}{|c|}{ The National Institute of Health consensus criteria (Fletcher criteria) } \\
\hline Very low risk & $<2.0$ & $! 5$ & Not considered \\
\hline Low risk & $2.0-4.9$ & $! 5$ & \\
\hline \multirow[t]{2}{*}{ Intermediate risk } & $! 5.0$ & $6-10$ & \\
\hline & $5.0-10.0$ & $! 5$ & \\
\hline \multirow[t]{3}{*}{ High risk } & $>5.0$ & $>5$ & \\
\hline & $>10.0$ & Any & \\
\hline & Any & $>10$ & \\
\hline \multicolumn{4}{|c|}{ Modified National Institute of Health consensus criteria (Joensuu criteria) } \\
\hline Very low risk & $<2.0$ & $! 5$ & Any \\
\hline Low risk & $2.1-5.0$ & $! 5$ & Any \\
\hline \multirow[t]{2}{*}{ Intermediate risk } & $! 5.0$ & $6-10$ & Gastric \\
\hline & $5.1-10.0$ & $! 5$ & Gastric \\
\hline \multirow[t]{6}{*}{ High risk } & Any & Any & Tumour rupture \\
\hline & $>10.0$ & Any & Any \\
\hline & Any & $>10$ & Any \\
\hline & $>5.0$ & $>5$ & Any \\
\hline & $! 5.0$ & $>5$ & Nongastric \\
\hline & $5.1-10.0$ & $! 5$ & Nongastric \\
\hline \multicolumn{4}{|c|}{$\begin{array}{l}\text { The Armed Forces Institute of Pathology criteria for size and mitosis count } \\
\text { (Miettinen criteria) }\end{array}$} \\
\hline Group 1 & $<2.0$ & $! 5$ & \multirow{8}{*}{$\begin{array}{l}\text { Separate analyses } \\
\text { available for gastric, } \\
\text { duodenal, ileal/jejunal } \\
\text { and rectal GISTs }\end{array}$} \\
\hline Group 2 & $2.1-5.0$ & $! 5$ & \\
\hline Group 3a & $5.1-10.0$ & $! 5$ & \\
\hline Group 3b & $>10.0$ & $! 5$ & \\
\hline Group 4 & $<2.0 \mathrm{~cm}$ & $>5$ & \\
\hline Group 5 & $2.1-5.0$ & $>5$ & \\
\hline Group 6a & $5.1-10.0$ & $>5$ & \\
\hline Group 6b & $>10.0$ & $>5$ & \\
\hline
\end{tabular}

GIST, gastrointestinal stromal tumour. rule, since some GISTs are insensitive to the drug imatinib in cases of PDGFRA exon 18 mutation D842V. ${ }^{11}$ Some consensus suggested that mutational analysis inclusion in the diagnostic work up of GISTs should be considered a standard practice. ${ }^{12}$

Surgery is the standard treatment for localised GISTs. The tumour should be removed en-bloc with its pseudocapsule to yield an adequate resection margin. The optimal width of the tumour-free margin has not been defined. Regional lymph node resection is of unproven value, since GISTs rarely metastasise to lymph nodes. Tumour rupture is associated with poorer outcomes and should be reported, as it carries a risk of tumour seeding. ${ }^{11} 12$

The presence of metastasis does not contraindicate surgery of the primary tumour, fwhile neoadjuvant imatinib should be considered for those large gastric or rectal primaries where immediate resection is likely to be morbid, for example total gastrectomy or abdomino-perineal resection. In such situations, mutational analysis is mandatory prior to the initiation of imatinib therapy. ${ }^{11}$

The introduction of adjuvant therapy (imatinib) has revolutionised the management of primary GISTs and should be considered a standard treatment in all patients with significant risk of recurrence following resection of primary GISTs. ${ }^{21}$ The standard therapy for imatinib is $400 \mathrm{mg}$ daily for 3 years, and randomised clinical studies are ongoing to test longer durations of adjuvant therapy. ${ }^{212} 21$ Patients who progress despite imatinib dose escalation or are intolerant to imatinib are candidates for dose escalation or a trial of other tyrosine kinase inhibitors such as sunitinib, a standard second line treatment. ${ }^{11}$

There are no published data to indicate the optimal routine follow-up policy of surgically treated tumours with localised disease. Such is the case with our patient with a suspect of recurrence 20 years after primary surgical excision before the imatinib era. Nowadays, it is recommended to do annual enhanced CT scan of the abdomen and pelvis for 5 years in low-risk patients after the surgery, and every 6 months for high-risk patients and those on adjuvant imatinib therapy. After that every 3-4 months for the first 2 years and every 6-12 months for 10 years from stopping imatinib. ${ }^{16}$ Relapses occur more often to the liver and peritoneum, and rarely to lung and bone. Risk assessment based on the mitotic count, tumour size and tumour site may be useful in choosing the routine follow-up policy. High-risk patients generally relapse within 1-3 years from the end of adjuvant therapy. Low-risk patients may relapse later, given that the disease is likely to be growing slowly. ${ }^{14}$

\section{Learning points}

The unusual occurrence of CD117-positive tumours outside the gastrointestinal tract questions the origin of such tumours from the interstitial cells of cajal and whether the parameters used for predicting the prognosis of GIST are suitable for EGISTs' evaluation.

- The origin, incidence and tumour behaviour of EGIST are a subject still to be investigated.

- Further research is needed in large series with long duration of follow-up to set up a tailored diagnosis and management guidelines for such type of tumours.

Contributors AAA has made substantial contributions to the conception, design of the work, the acquisition, analysis, interpretation of data, have drafted the work and revised it. She has approved the submitted form and agreed both to be personally accountable for the author's own contributions and to ensure that questions related to the accuracy or integrity of any part of the work, even ones in which the 
author was not personally involved, are appropriately investigated, resolved and the resolution documented in the literature. GB has contributed to the conception, design of the work, the acquisition, analysis, has revised the work and approved the submitted form.

Funding The authors have not declared a specific grant for this research from any funding agency in the public, commercial or not-for-profit sectors.

Competing interests None declared.

Patient consent for publication Obtained.

Provenance and peer review Not commissioned; externally peer reviewed.

Open access This is an open access article distributed in accordance with the Creative Commons Attribution Non Commercial (CC BY-NC 4.0) license, which permits others to distribute, remix, adapt, build upon this work non-commercially, and license their derivative works on different terms, provided the original work is properly cited and the use is non-commercial. See: http://creativecommons.org/ licenses/by-nc/4.0/.

\section{ORCID iD}

Arwa Ahmed Ashoor http://orcid.org/0000-0002-8831-712X

\section{REFERENCES}

1 Tryggvason G, Gíslason HG, Magnússon MK, et al. Gastrointestinal stromal tumors in Iceland, 1990-2003: the Icelandic GIST study, a population-based incidence and pathologic risk stratification study. Int J Cancer 2005;117:289-93.

2 Fülöp E, Marcu S, Milutin D, et al. Gastrointestinal stromal tumors: review on morphology, diagnosis and management. Rom J Morphol Embryol 2009;50:319-26.

3 Rossi CR, Mocellin S, Mencarelli R, et al. Gastrointestinal stromal tumors: from a surgical to a molecular approach. Int J Cancer 2003;107:171-6.

4 Miettinen M, Felisiak-Golabek A, Wang Z, et al. Gist manifesting as a retroperitoneal tumor. Am J Surg Pathol 2017;41:577-85.

5 Feng F, Feng B, Liu S, et al. Clinicopathological features and prognosis of mesenteric gastrointestinal stromal tumor: evaluation of a pooled case series. Oncotarget 2017:8:46514-22.

6 Wronski M, Cebulski W, Slodkowski M, et al. Gastrointestinal stromal tumors. Journal of Ultrasound in Medicine 2009;28:941-8.
7 Foo WC, Liegl-Atzwanger B, Lazar AJ. Pathology of gastrointestinal stromal tumors. Clin Med Insights Pathol 2012;5:CPath.S9689.

8 Rajendra R, Pollack SM, Jones RL. Management of gastrointestinal stromal tumors. Future Oncol 2013:9:193-206.

9 Fletcher CDM, Berman JJ, Corless C, et al. Diagnosis of gastrointestinal stromal tumors: a consensus approach. Int I Surg Pathol 2002;10:81-9.

10 Sanchez-Hidalgo JM, Duran-Martinez M, Molero-Payan R, et al. Gastrointestinal stromal tumors: a multidisciplinary challenge. World I Gastroenterol 2018;24:1925-41.

11 Judson I, Bulusu R, Seddon B, et al. Uk clinical practice guidelines for the management of gastrointestinal stromal tumours (GIST). Clin Sarcoma Res 2017;7.

12 Casali PG, Abecassis N, Bauer S, et al. Gastrointestinal stromal tumours: ESMOEURACAN clinical practice guidelines for diagnosis, treatment and follow-up. Ann Oncol 2018:29.

13 Nishino M, Hayakawa K, Minami M, et al. Primary retroperitoneal neoplasms: CT and MR imaging findings with anatomic and pathologic diagnostic clues. Radiographics 2003;23:45-57.

14 Gutierrez JC, De Oliveira LOP, Perez EA, et al. Optimizing diagnosis, staging, and management of gastrointestinal stromal tumors. J Am Coll Surg 2007;205:479-91.

15 Hong X, Choi H, Loyer EM, et al. Gastrointestinal stromal tumor: role of CT in diagnosis and in response evaluation and surveillance after treatment with imatinib. Radiographics 2006;26:481-95.

16 King DM. The radiology of gastrointestinal stromal tumours (GIST). Cancer Imaging 2005;5:150-6.

17 Levy AD, Remotti HE, Thompson WM, et al. Gastrointestinal stromal tumors: radiologic features with pathologic correlation. Radiographics 2003;23:283-304.

18 Joensuu H, Vehtari A, Riihimäki J, et al. Risk of recurrence of gastrointestinal stromal tumour after surgery: an analysis of pooled population-based cohorts. Lancet Oncol 2012;13:265-74

19 Miettinen M, Lasota J. Gastrointestinal stromal tumors: review on morphology, molecular pathology, prognosis, and differential diagnosis. Arch Pathol Lab Med 2006;130:1466-78.

20 Miettinen M, Lasota J. Gastrointestinal stromal tumors: pathology and prognosis at different sites. Semin Diagn Pathol 2006;23:70-83.

21 Reichardt P, Blay J-Y, Boukovinas I, et al. Adjuvant therapy in primary GIST: state-ofthe-art. Ann Oncol 2012;23:2776-81.

Copyright 2020 BMJ Publishing Group. All rights reserved. For permission to reuse any of this content visit https://www.bmj.com/company/products-services/rights-and-licensing/permissions/

BMJ Case Report Fellows may re-use this article for personal use and teaching without any further permission.

Become a Fellow of BMJ Case Reports today and you can:

- Submit as many cases as you like

- Enjoy fast sympathetic peer review and rapid publication of accepted articles

- Access all the published articles

- Re-use any of the published material for personal use and teaching without further permission

Customer Service

If you have any further queries about your subscription, please contact our customer services team on +44 (0) 2071111105 or via email at support@bmj.com.

Visit casereports.bmj.com for more articles like this and to become a Fellow 